\title{
Case Analysis on Psychological Consult of Negative Emotion of College Students
}

\author{
Jian Gao \\ Nanjing Forestry University \\ Nanjing, China
}

\begin{abstract}
With the increasing pressure of learning and living, in recent years, the contemporary college students have been obsessed by the psychological problems caused by negative emotions. They often have negative emotions due to many factors, such as being crossed in love, decline in academic performance, family problems, etc., resulting in serious sense of loss, unstable emotion, impulsiveness blind and other symptoms, which may cause more adverse effects to the society. Based on the rational analysis and logic argument on a female college student's negative emotional problems caused by being crossed in love, this case analysis connects with the characteristics of personality of students, sets up periodical therapeutic goals, actively absorbs the relevant ideas of psychology, introduces emotional guidance method, so as to help the visitors to overcome emotional problem and get out of emotional disturbance. This paper introduces the purpose and methods of emotional guidance method and the related practice of positive psychology, and aims to help the contemporary college students who are deeply influenced by negative emotions to improve their ability to deal with negative emotions, understand themselves, accept themselves, and establish their own goals.
\end{abstract}

Keywords-college students; negative emotions; psychological guidance; emotional guidance method

\section{INTRODUCTION}

At present, higher education has shown unprecedented development momentum and the scale of running schools has continued to expand. However, at the same time, the individual behavioral bias caused by psychological problems in the student group has also been increasing. Especially, the psychological problems caused by negative emotions have been increasingly concerned by education sector and society. Negative emotions, also known as negative induced emotions, refer to individual unhealthy emotions caused by people's subjective needs inconformity with the external environment when they are living, studying and working. The negative emotions of contemporary college students mainly come from the people, things and objects that are not in line with their psychological needs during the college life, such as the problems of breakup, family and unstable learning state. Once these negative emotions are produced, they will inevitably affect the life and learning of college students. If negative emotions cannot be adjusted well, they will accumulate repeatedly, which may result in that the college students will suffer self-harm, harm others, and even move toward the road of crime.
The author once addressed a case that a college student who was negatively affected by her negative emotions. Through rational analysis and logic argument, the author adopted emotional guidance method and assisted the visitor to change unreasonable ideas, overcome the negative emotions, shake off the emotional disturbance and start a new learning life. The case summary is reported as follows

\section{BASIC INFORMATION}

\section{A. Demographic Data}

Xiao Huang (assumed name), female, 20 years old, a freshman in a university, is the only child in her family. Her parents are all ordinary employees and her family background is common.

\section{B. Personal Growth History}

Xiao Huang is introverted and does not like to communicate with others. She has single lifestyle, narrow interest and closed mind. Since childhood, Xiao Huang's parents have higher requirements for her, which leads to that she has formed a concept that everything is demanding perfection and gradually developed forced psychology and low self-esteem. Due to many times she has spent in learning and her own personalities, Xiao Huang rarely interacts with students of the opposite sex and has a certain misunderstanding on love.

\section{Mental State}

Her mental state is in not good condition, emotion is low and thought is relatively clear. She has deeply realized her own problems and has strong desire for help.

\section{Social Function}

Social function has not been significantly damaged and has not yet seriously affected normal learning and classmate relations.

\section{Chief COMPLAint AND PERSONAl StATEMENT}

\section{A. Chief Complaint}

Xiao Huang is introverted since children and forms strong self-abasement tendency due to the pressure brought by her family. Because of the lack of interest and small 
communication space, Xiao Huang rarely interacts with students of the opposite sex. After studying in the university, she fall in love with a boy secretly and mistakenly believes that the boy is also interested in her. Recently, Xiao Huang finds that the boy already has girlfriend, thus she thinks that she is to be fooled and feels strong loneliness and helplessness. Therefore, her inferiority complex has been aggravated and her emotions have become more extreme. She is more confused about the future and has lost the future goal.

\section{B. Personal Statement}

Since children, I want to be an excellent and useful person, which not only reflects in study, bearing oneself, but also embodies in the future job. However, I have not done anything well and I even do not like myself.

One point I must admit is that I am really naive and I think the life is too easy. The relationship between him and I develops to where it is today and I think most of the reasons lie in me. The biggest mistake he made was that he liked a girl whom I didn't like very much, and he still kept this thing from me and made me have fantasy about him.

My wishes for him are that I want to stay with him, learn with him in the university and live together after graduation. Now, it seems that this idea is wrong. Life is really not that easy, but I don't understand why it is not easy. In my opinion, you like me and I like you, why cannot we stay together?

Now I do not blame him at all, but I am very reluctant. For him, I can only choose to forget, bless him, and never see him again. I'm going to be better than him. Don't let him worry and don't let them look down on me.

The biggest confusion now is: How to correct myself, how to adjust my own values and outlook on life, and how to plan my own life. Now I feel that everything is chaotic.

\section{OBSERVATION AND OTHER'S REFLECTION}

\section{A. Observation in Consulting}

The visitor came to the consultation with a general mood and a neat dress, but she gave the impression of cowardice and shyness. After she was seated, I found that her mood was obviously low, her eyes couldn't look straight ahead, she was not good at communicating with others, and she couldn't verbally elaborate on the things she wanted to consult. After that, I advised her to communicate with me by means of letters and she assented. In the first letter from the visitors, her train of thought was clear, and she had elaborated the cause and effect of her affairs, had a deeper understanding on her problems and had a strong desire to solve the problem. However, this letter revealed her low self-esteem, disappointment, concern and confusion for the future in the lines

\section{B. Other's Reflection}

According to the reflection of classmates in dormitory, the relationship between Xiao Huang and her classmates has always been relatively harmonious. She studies very hard and often takes the initiative to clean the dormitory in daily life.
However, Xiao Huang is more introverted, especially after emotional problems occurred, she has no more words to say. She is often in low spirit and more confused about the future, with pessimistic mood. Other aspects are normal.

\section{PSYCHOLOGICAL ASSESSMENT AND DIAGNOSIS}

\section{A. Psychological Test}

Use symptom checklist (SCL-90), self-rating depression scale (SDS) and self-rating anxiety scale (SAS) to carry out psychological test. The test result shows: the total points of SCL-90 are 289, and positive project is 87 and all the factors were positive. Among which, the three highest scores are interpersonal sensitivity, obsessive-compulsive symptoms, and depression, which are 4.05, 3.85, and 3.75, respectively. The standard score of SDS is 64, regarded as moderate depression. The standard score of SAS is 59, regarded as mild anxiety.

\section{B. Etiology Analysis}

The psychological characteristics of being introverted, pursuing perfection, and individuality and sensitivity often cause someone to be stuck in an anxious and depressed state, and they are unwilling to communicate with others, which also makes this pessimistic mood unresolved for a long time. They usually have irrational cognition and passive self-suggestion. Their communication circle is narrow and they rarely contact with the opposite sex, resulting in having misconception about their classmates of opposite sex and forming the wrong view of love.

\section{Diagnosis}

The visitor's cognition is consistent with her emotional expression, and she has self-consciousness for her psychological problems, has the initiative to seek medical treatment, has no disordered logical thinking, and has no psychotic symptoms, such as fantasy and delusion. Therefore, her mental disease can be excluded, however, her anxiety and depression have obvious reasons. The recent negative emotions are not generalized, and their reaction intensity is understandable. This does not seriously affect normal learning and relationship with classmates. She has a desire to seek for help. Therefore, the psychological diagnosis of the visitor is the general psychological problems caused by negative emotions.

\section{DETERmination OF CONSUlting GoAls}

Based on the assessment and diagnosis above, we negotiate with the visitor to determine the following consulting goals:

\section{A. Primary Goals}

Transfer your attention from emotional problems to other aspects, realize your irrational thinking on things, and see and evaluate yourself again. Explore your own advantages, build confidence, and reduce anxiety. 


\section{B. Intermediate Goals}

Further affirm yourself, overcome the adverse effects arsing from negative emotions, adjust your demands, and fully realize the difference between reality and ideal. Cultivate a good attitude to face setbacks, change the original view of love and life, and reshape your cognitive model.

\section{Ultimate Goals}

Learn to mentally regulate yourself, actively explore your advantages, enhance self-confidence, establish a correct view of love and life, promote the perfection of personality and comprehensive development of body and mind, set a clear goal and direction for future life and learning.

\section{EMOTIONAL DREDGING METHOD}

\section{A. Principles and Purposes}

From an information medicine perspective, human brain is not an all-embracing repository. Positive and healthy information play a role of affinity, harmony, and "massage" protection to the brain. Negative information will produce bad stimulation, which can only increase the mental burden, cause the dysfunction of the nervous system, weaken the immune mechanism of the body, accelerate the aging of the brain cells, and lead to life disorder and deterioration of the physical and mental state. The emotional dredging method emerges based on this theoretical basis. The point of emotional dredging method is in the two words of "dredging" and "blocking". We take measures that conform to the visitor's personality characteristics to help her to forget or transform negative information and negative emotions, and then deliver positive energy to her. With the combination of dredging and blocking, the patient's psychological problems will be successfully cured.

\section{B. Specific Practices}

1) Change the way of communication according to patient characteristics: As the visitor is emotionally frustrated, she denies herself, and feels that she does not have the ability to love and be loved, thus causing a certain degree of anxiety. Meanwhile, because of her own personality characteristics, she has a certain error in the concept of love and life, which results in a large number of negative emotions gathered. By summarizing the experience of past cases, faced with this situation, visitor needs to open her heart in the first, and then pour out all her own feelings.

However, in the process of first consultation, the author discovered that Xiao Huang was extremely introverted, and it was difficult for her to tell her inner feelings through verbal communication. In the face of this situation, the author no longer forced Xiao Huang to have communication, instead, the author negotiated with her to communicate by letter. The results show that the transformation of communication methods has greatly improved communication efficiency and laid a solid foundation for follow-up treatment.

2) Screen cognitive delusions and transfer negative emotions: Through careful screening, the patient has been in a state of unrequited love in this matter. Aiming at this fact, the author first pointed out the mistakes of the boy in the reply to the patient, and analyzed the boy's original intentions for the patients, so as to relieve Xiao Huang's psychological pressure and made her realize that it was not that she was not good enough to lead to a series of incidents.

Next, the author has been trying to correct the original wrong love concept of Xiao Huang. Love does occupy an important position in life. Life without love is indeed imperfect, but love is neither the foundation of life, nor the whole of life, and it is pale to live for love only. During the consultation, the author has enumerated many examples about celebrity's lovelorn. Though setting example, such as Goethe, Beethoven, Roman Roland and other celebrity role models, the author has suggested that Xiao Huang should develop a interest and hobby and make some friends to actively transfer the pain of lovelorn, and then start a new life.

3) Use positive psychology to rebuild confidence: Positive psychology is a new research trend that emerged in the Western psychology circle at the end of the 20th century. It has puts the focus on the positive factors of human beings, proposed that psychology should start with human's inherent centurial constructive strength, virtue and goodness, and advocate the use of a positive attitude to make new interpretations of human's many psychological problems, so as to stimulate people's internal positive strength and excellent quality. In addition, it has used these positive forces and excellent quality to help people with problems, ordinary people or talented people to maximize their potential and interact well with the life.

The visitor is introverted, sensuous and self-abased. She has a negative self-assessment, and believes that others are better than her in all aspects. She has higher demands for herself, and unilaterally considers issues in terms of emotional problems. She has a poor anti-frustration ability after being attacked, and is confused about the future. These negative emotions above lead to her psychological problems. Therefore, the author has used method of reverse psychological adjustment to change the perspective of this lovelorn incident in specific consultation, and inspired Xiao Huang to think that this friendship may not be so important to herself and they may not be very suitable, and this relationship will also become a wealth of life. The author also will help Xiao Huang draw a bright future blueprint, actively guide her to tap her own advantages and face life again.

\section{EFFECT EVALUATION}

\section{A. Visitor's Self-assessment}

After several consultations, Xiao Huang's mood gradually began to be clear. She could face up to herself, realizes the influence of unreasonable beliefs on herself, and understands how to think in a rational way. She becomes confident and relaxed, and sunny and positive. Her depression has improved significantly, and her learning and life have been on the right track. What's more, Xiao Huang has accepted the author's advice and begun to make more contacts with the society and make friends. 


\section{B. Consultants' Observation and Evaluation}

The visitor is in a good mental status, becomes confident and optimistic, and has goals and plans for the future. In the communication with her classmates, Xiao Huang has become outgoing, can take the initiative contact with others, and has been talkative. Xiao Huang's learning initiative has improved and her academic performance has also improved.

\section{Psychological Review}

The test results show: the total score of SCL- 90 is 153 , and the number of positive items is 42; SDS: the standard score is 42; SAS: the standard score is 40. All above are in the normal range. It shows that the depression and anxiety of the help seeker has been alleviated, and the expected goal has been achieved. Thanks to the active cooperation of the visitor, the psychological consultation in this case has achieved satisfactory results.

\section{CONCLUSION}

College students who have negative emotions due to various factors have mental symptoms or abnormal behaviors. During the consultation in this case, the consultant has given the visitor unconditional acceptance, respect and positive attention, established a safe, trusted, friendly and interactive relationship with the visitor. The consultant changes and influences visitor's bad psychological state and behavior through his behaviors such as good appearance, language, manners and emotion, which promotes the visitor's selfexploration and self-knowledge, as well as the change of the her thinking mode.

\section{REFERENCES}

[1] Li Jinzhen, Wang Wenzhong, Shi Jiannong. Positive Psychology: A New Trend in Psychology. Advances in Psychological Science. 2003 (11).

[2] Zhang Yu. On Negative Emotional Characteristics and Self-Mediation Strategies of Contemporary College Students. Theory of Mental Health, 2009 (6).

[3] Kong Qingrong. On the Influence of Negative Emotions on College Students' Mental Health. Education and Vocation, 2011 (11).

[4] Zhang Suxia. Negative Sentiment of the College Students and Psychological Nursing. Occupation and Health, 2007 (23).

[5] Hu Yue, Huang Hai, Zhang Yuqing, Zhou Chunyan. The Mediating Effect of Negative Emotions between Mobile Phone Dependence and Cognitive Failure. Chinese Journal of Clinical Psychology, 2017 (6). 